\title{
Continuous Monitoring of IgG using Immobilized Fluorescent Reporters
}

\author{
Atul Goyal ${ }^{1}$, Binh $\mathrm{Vu}^{1}$, Vijay Maranholkar ${ }^{1}$, Ujwal Patil ${ }^{2}$, Katerina Kourentzi ${ }^{1}$, and \\ Richard Willson ${ }^{1}$ \\ ${ }^{1}$ University of Houston \\ ${ }^{2}$ University of Houston System
}

January 4, 2022

\begin{abstract}
In the manufacture of therapeutic monoclonal antibodies (mAbs), the clarified cell culture fluid is typically loaded onto an initial protein A affinity capture column. Imperfect mass transfer and loading to maximum capacity can risk antibody breakthrough and loss of valuable product, but conservative underloading wastes expensive protein A resin. In addition, the effects of column fouling and ligand degradation require the frequent optimization of IgG loading to avoid wastage. Therefore, continuous realtime monitoring of IgG flowthrough is of great interest. We previously developed a fluorescence-based monitoring technology that allows mix-and-read mAb detection in cell culture fluid. Here we report the use of reporters immobilized on CNBr-activated Sepharose 4B resin for continuous detection of IgG in column breakthrough. The column effluent is continuously contacted with immobilized fluorescein-labeled Fc-binding ligands to produce an immediately detectable change in fluorescence intensity. The technology allows rapid and reliable monitoring of IgG in a flowing stream of clarified cell culture fluid emerging from a Protein A column, without prior sample preparation. We observed a significant change in fluorescence intensity at $0.5 \mathrm{~g} / \mathrm{L}$ human IgG, sufficient to detect a $5 \%$ breakthrough of a $10 \mathrm{~g} / \mathrm{L}$ load, within 2 minutes at a flow rate of $0.5 \mathrm{~mL} / \mathrm{min}$.
\end{abstract}

\section{Hosted file}

Main text file.docx available at https://authorea.com/users/453931/articles/551695continuous-monitoring-of-igg-using-immobilized-fluorescent-reporters 


$$
2+2
$$



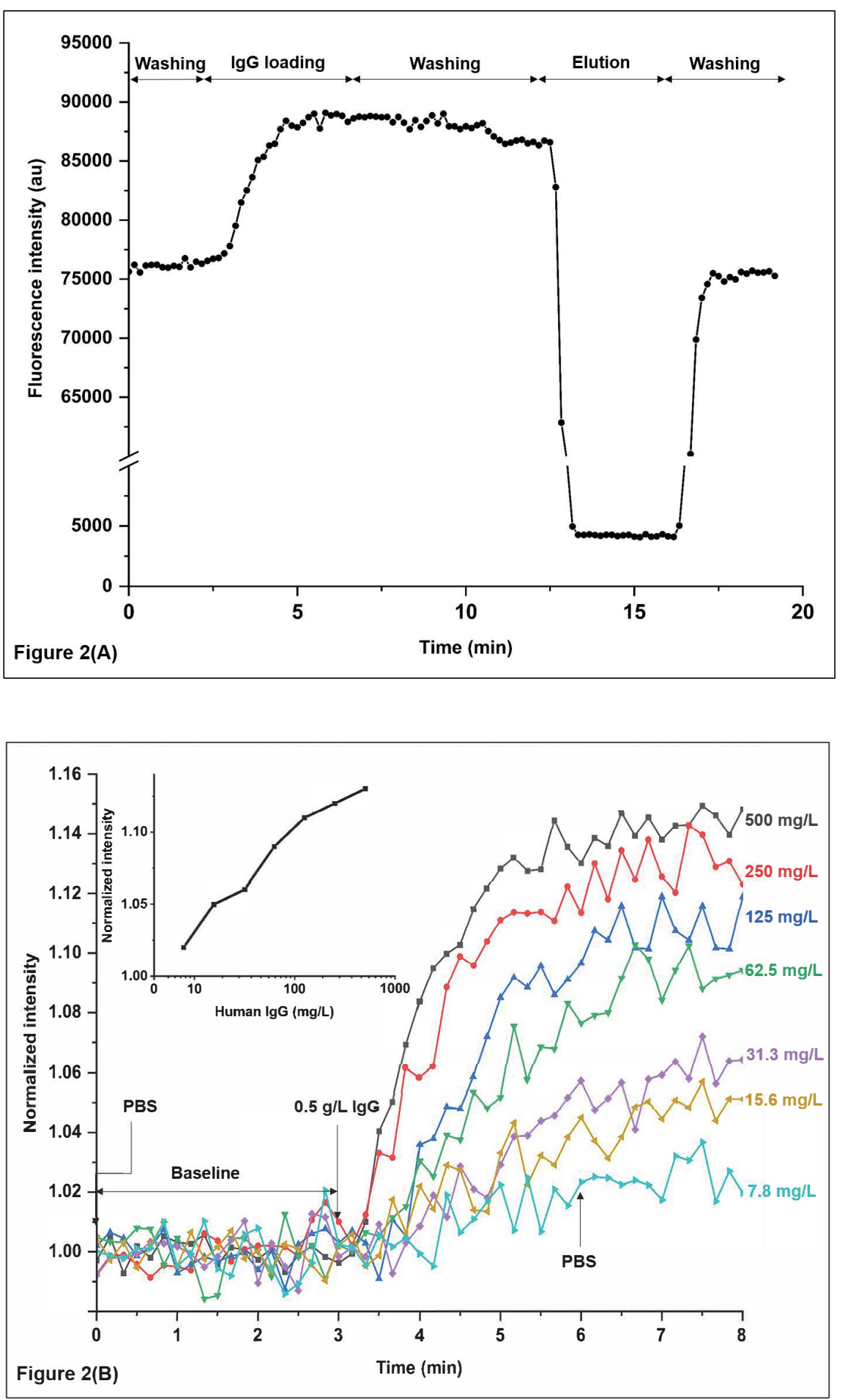

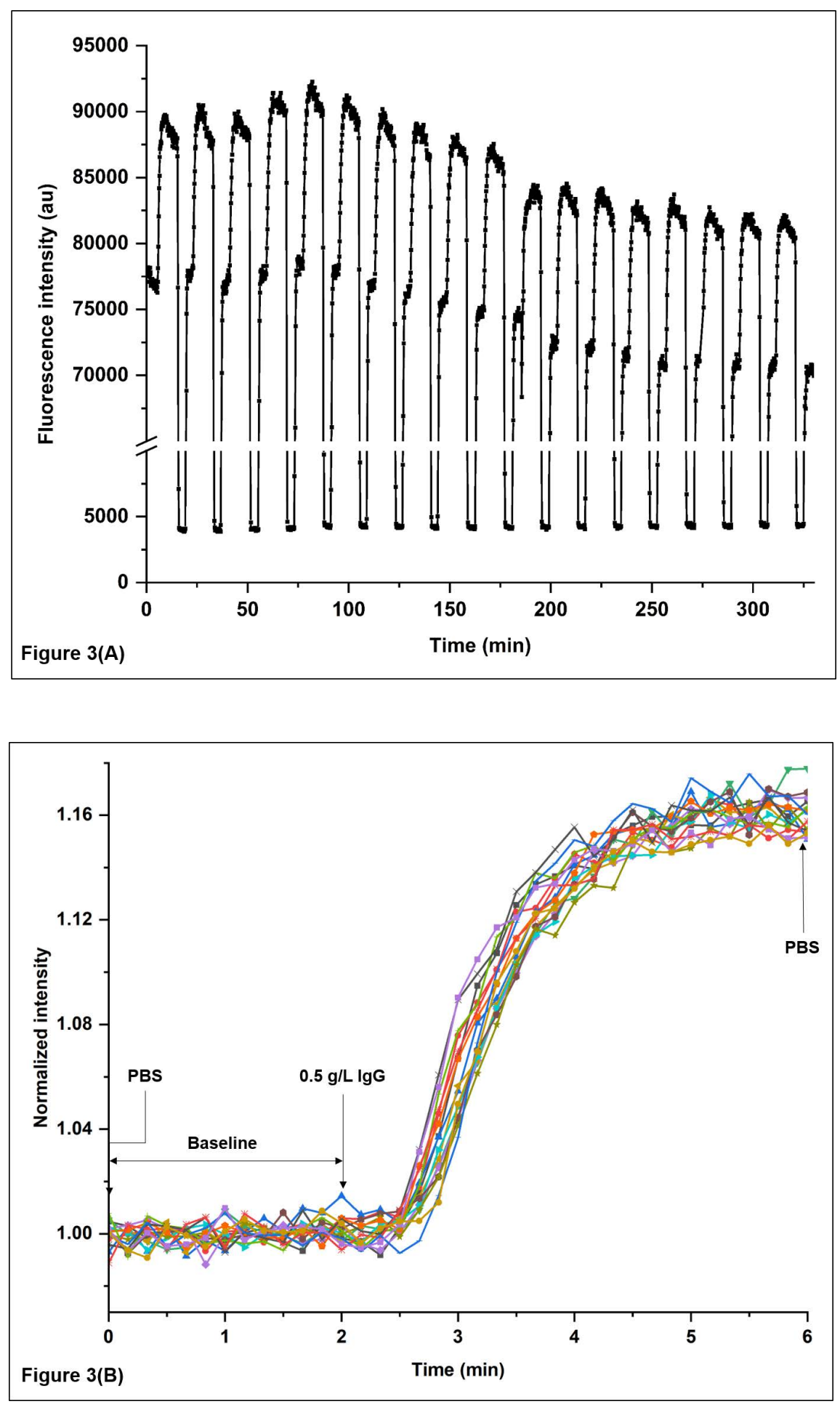

4 

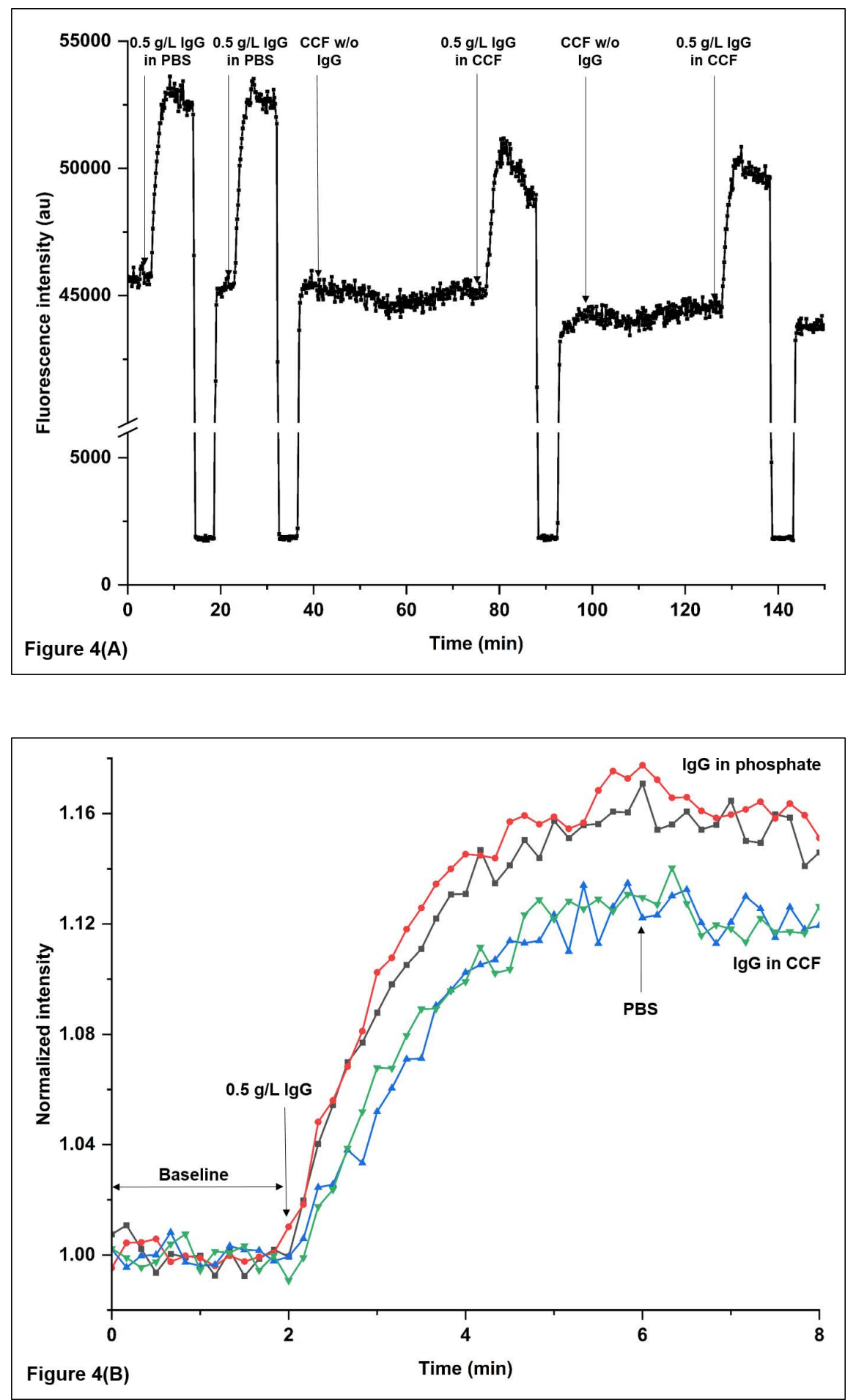